\title{
Assessing The Impact Of Medical Malpractice Awards, Tort Reform, And Investment Returns Upon Medical Malpractice Insurance Premiums
}

William J. Smith, University of West Georgia, USA

Tania A. Celis, University of West Georgia, USA

Bruce M. Bird, University of West Georgia, USA

\begin{abstract}
For most doctors, obtaining medical malpractice insurance coverage each year represents a significant expense. During the past three decades, researchers have developed several competing theories to explain changes in the cost of obtaining medical malpractice insurance in the United States. This article focuses on the relationship, on a nationwide basis, between medical malpractice awards, the presence of tort reform, investment returns by insurers, and the impact of each upon the cost of obtaining medical malpractice insurance. The results of a multivariate equation are then used to analyze the relative impacts of these competing theories.
\end{abstract}

Keywords: Medical Malpractice Awards; Medical Tort Reform; Investment Returns By Insurers; Medical Malpractice Insurance Premiums

\section{INTRODUCTION}

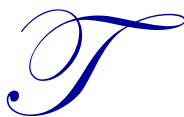

he past three decades have witnessed dramatic changes in medical malpractice insurance premiums. ${ }^{1}$ A spirited debate has ensued regarding which factors are most significant in explaining the changes in such premiums over time. One theory is that a decrease in an insurer's return on its investment portfolio has the effect of increasing medical malpractice insurance premiums. A second is that malpractice premiums are the direct result of medical malpractice awards and settlements. Stated alternatively, states having higher than average medical malpractice awards also tend to have higher than average malpractice insurance premiums $^{2}$. A third theory is that an increase in passage of state-level tort reform changes the likelihood of massive settlements or judgments in malpractice cases, and thus, such legislation has the effect of decreasing such premiums by reducing insured risk.

In many parts of the U.S., during certain time periods, medical costs have risen faster than the overall rate of inflation. Rising medical malpractice insurance premiums represent a cost that some doctors may decide to pass along to their patients in the form of higher prices for medical services rendered. It is also possible that the perceived threat of medical malpractice litigation may result in some doctors providing additional precautionary medical services to their patients. ${ }^{3}$

\footnotetext{
${ }^{1}$ Neale, F. Eastman, K. Drake, P. (2009). Dynamics of the Insurance Market for Medical Malpractice Insurance. Medical malpractice insurance provides coverage for members of the medical profession for liability resulting from claims of professional negligence. The Journal of Risk and Insurance, 2009, Vol.76, No.1, pg 221-47, pg. 221. Changes in medical malpractice insurance premiums are typically computed on an inflationadjusted, per-doctor basis. See Appendix 1.

${ }^{2}$ Moreover, time periods in which higher than average medical malpractice awards occur are the same time periods in which higher than average medical malpractice insurance premiums occur.

${ }^{3}$ A study by Dubay, Kaestner and Waidmann (1999) provides evidence that physicians are more likely to order unnecessary cesarean procedures in obstetrics to avoid litigation, but that the impact of increased cesarean sections to mitigate malpractice lawsuits on total obstetric care costs is 
This research focuses upon the relationship, on a nationwide basis, between medical malpractice awards, insurers' return on investments, the presence of tort reform, and the cost of medical malpractice insurance premiums. Because many insurers operate in more than a single state, it would be difficult to conclude that all of the costs associated with massive jury awards, settlements, or gains/losses accruing from insurance companies' investments would be confined to a single state, regardless of the current legislative climate involving malpractice ${ }^{4}$. Based on this, we estimate the cost of medical malpractice insurance premiums for the nation overall using the following independent variables: malpractice awards, insurers' return on investments, and the existence of tort reform. We focus primarily upon the results of a multivariate regression to analyze the above-mentioned theories that compete to explain changes in the cost of medical malpractice insurance in the U.S.

\section{Literature Review}

A number of researchers have analyzed the rise in medical malpractice insurance premiums (Gius, 1998; Helland \& Showalter, 2009; Hillman \& Cluff, 2003; Kessler, 2006; Kilgore, Morrisey, \& Nelson, 2006; Lai \& Witt, 1992; Neale, Eastman, \& Peterson Drake, 2009; Viscusi \& et al., 1993). Most of the research during the 1990s and 2000s use aggregate premium revenues as a proxy for malpractice premium levels. Depending on the years under observation, researchers have found varying levels of impact associated with state-level malpractice liability limitations. Lai and Witt (1992) examined the effect of insurer expectations upon the supply and cost of premiums. Lai and Witt sought to explain the growth rate of premiums in terms of 1) the change in the growth rate of losses and expenses; and 2) the variance in the growth rate of expenses. Their research concluded that increases in the mean and dispersion of losses and expenses did explain the increase in premiums.

Gius (1998), using a long time-series data set, found that malpractice liability limitations had virtually no effect on insurers' aggregate premium revenues. In a study using a shorter time-series data set, Viscusi et al. (1993) found that some limitations on medical malpractice liability resulted in substantial and statistically significant reductions in aggregate premiums. Nelson, Morrisey, and Kilgore (2006) suggest that, regarding the findings of recent research, the question is about the magnitude of the impact that liability limitations have on aggregate premium revenues, rather than whether or not such an impact exists. The research of Neale et al. suggests that shorter, more rigorous, empirical studies tend to point to liability limitations resulting in significant aggregate premium reductions with relatively large magnitudes, while works that use longer time series tend to result in smaller estimated impacts on premium revenue (or revenue growth) over time.

In "Dynamics of the Market for Medical Malpractice Insurance", Neale et al. (1992) built upon Lai and Witt's prior research. Neale et al. examined the stability of the market for medical malpractice insurance by analyzing financial data from 1993-2003 collected by the National Association of Insurance Commissioners (NAIC). The variables analyzed by Neale et al. included the number of insurers writing medical malpractice insurance, the relationship between growth rates of premiums and losses, variance losses, and investment income. The research of Neale et al. differs methodologically from that of Lai and Witt. Neale et al. consider "losses incurred" rather than "losses paid". 5 The variable "losses incurred" takes into account the fact that insurers price their policies based upon expected future losses. Accordingly, "losses incurred" is thought to allow for flexibility in testing changing expectations.

Neale et al. sought to confirm the presence of market instability in the data they analyzed. To do this, they chose to use the bivariate Granger causality model. It allows for the estimation and comparison of the explanatory strength of two variables for purposes of determining whether past losses predict premiums, or, in the alternative, whether past premiums predict losses. Neale et al. noted that the first relationship contained more explanatory

\footnotetext{
relatively small and varies with the socioeconomic status of the mother.

${ }^{4}$ Scant information exists regarding the potential for malpractice insurance providers spreading their costs (or losses) directly (or indirectly) across state lines. The implicit assumption of most arguments made in favor of comprehensive malpractice and tort reform is that malpractice awards are confined to a single state, and as such, the impact of massive jury awards or settlements will only be important for insurance costs, and subsequently medical costs, within that particular state where the award or settlement occurred. If, however, malpractice insurance companies operate in multiple states, there is the possibility that tort reform legislation in one state will have spillover impacts on insurance costs in other states without caps on malpractice payouts, and payouts in states without caps may have the effect of increasing premiums in states with caps.

${ }^{5}$ By way of analogy, "losses incurred" is more akin to an accrual-based accounting concept, whereas "losses paid" is more akin to a cash-basis accounting concept.
} 
power than the second. Thus, a causal relationship exists between direct losses and net premiums written. ${ }^{6}$ The authors found that, of the years examined, 2001 turned out to be the most unstable. Stated alternatively, the most significant misalignment between direct losses incurred and net premiums written occurred in 2001.

After establishing the presence of market instability, Neale et al. set out to examine the effect of selected variables (growth rates of net premiums written, direct losses incurred, direct defense and cost containment fees, and total losses incurred) upon the market over time. The authors recognized that the data might be distorted by the fact that insurers may 1) enter a market when few net premiums are written and there are little or no direct losses; and/or 2) leave a market when few net premiums are written but there are large direct losses. To account for such distortion, both mean and median growth rates were considered. Neale et al. observed that the median growth rate of direct losses incurred increased in all years except 1995, 1998, and 2000. The authors deduced that "losses, premiums, defense costs, and claim containment fees do not necessarily grow in a similar manner"7.

In testing for the effects of changes in the variables over time, Neale et al. expected that a strong, positive relationship between premiums and losses would continue to exist over time. Premiums and losses were expected to increase at the same natural rate so long as the rate of investment income growth remained constant. To test this, Neale et al. used geometric growth rates to reduce the risk of bias. ${ }^{8}$

The performance of insurers over time revealed that the growth of policyholder surplus has declined since 1994 while the growth in net investment income has steadily deteriorated from 1993 to 2000 . The authors concluded that insurers' actions to increase premiums are justified because the growth rate of losses has exceeded the growth rates of premiums. Thus, the instability in medical malpractice insurance appears to be driven by the direct losses incurred by the insurance companies. Furthermore, the data suggest that changes in the underwriting and legal systems do contribute to the growth of losses and related growth of medical malpractice insurance premiums.

A General Accounting Office (GAO) study analyzed data relating to seven states: California, Florida, Minnesota, Mississippi, Nevada, Pennsylvania, and Texas ${ }^{9}$. The GAO study sought to 1) describe the extent of increases in medical malpractice insurance rates; 2) analyze the factors that contributed to those increases; and 3) identify changes in the medical malpractice insurance market that might make premium rates different from that of past periods (most notably the periods from 1970-75 and 1975-1989).

The GAO concluded that insurers' losses, declines in investment income, a less competitive climate, and climbing reinsurance ${ }^{10}$ rates have all contributed to changes in premium rates. Analysis by the GAO identified increased losses on claims as the primary contributor to higher medical malpractice premium rates. The 15 largest medical malpractice insurers in 2001 (with a combined market share of 64.3\%) incurred losses (including both payments to plaintiffs to resolve claims and the costs associated with defending those claims) of approximately $78 \%$ of the insurer's total expenses. Because insurers base their premium rates on their expected costs, the GAO indicated that anticipated losses were the primary determinant of premium rates.

In all seven states sampled, aggregate incurred losses increased substantially after 1998. Mississippi and Pennsylvania experienced the highest increases (197.5\% and $97.2 \%$, respectively). The GAO anticipated that paid losses -- and, thus, premium rates -- would continue to rise from 2003-2006 in accordance with insurers' higher expectations of losses.

The GAO also explored the effect of tort legislation enacted into law in the mid-1970s that occurred in some of the states that it sampled. Such legislation is designed to reduce insurers' losses by limiting the number of claims filed, the size of awards and settlements, and the time and costs associated with resolving claims. For the states which did not enact tort reform, the GAO anecdotally observed the effects of imposed caps on non-monetary

\footnotetext{
${ }^{6}$ Neale et al. (1992). p 231. It should be noted that the causality was not consistent each year.

${ }^{7}$ Id at $\mathrm{p} 233$.

${ }^{8}$ By way of contrast, Lai and Witt used arithmetic growth rates.

9 Hillman, R., \& Cluff, L. (2003). Medical malpractice insurance: multiple factors have contributed to increased premium rates (GAO-03-702).

United States General Accounting Office. Washington, D.C.

${ }^{10}$ Reinsurance is also known as excess loss coverage.
} 
losses such as pain and suffering. Both tort reform and caps on non-monetary losses led to a reduction in the severity and frequency of claims filed in those states. As such, the expectations of insurers' losses may have been affected by past -- or the potential for future -- tort legislation, resulting in lower real insurance costs per doctor in the mid-2000s.

In "The Determinants of the Cost of Medical Liability Insurance", Kessler (2006) analyzed data from the Texas Department of Insurance (TDI) and the National Association of Insurance Commissioners (NAIC). Kessler observed that approximately $87 \%$ of malpractice insurers' expenses consisted of direct losses plus loss adjustment expenses incurred. Further, Kessler noted that, according to the NAIC, total incurred losses in medical malpractice increased in real terms by $178.2 \%$ from 1991 to 2003 (94.5\% per capita). Kessler observed: "If other insurers' expenses remained roughly constant, a very simple, competitive model of the industry would predict that premium rates should have increased by approximately $82 \%,{ }^{11}$ strikingly similar to the increase of $71 \%$ in the professional liability insurance component of the CMS Medicare Economic Index Market Basket” (Kessler 2006, 15).

Other variables explored by the GAO and Neale et al were considered by Kessler as only marginally explanatory regarding the increase of premium rates. Kessler noted that "low entry barriers, declines in insurer investment income or increases in health care costs can account for at most a small fraction of the increase in premiums" (Kessler 2006, 23). Kessler concluded that increases in tort awards, settlement payments, and defense costs explain why premiums have risen. Accordingly, reforms to the tort laws of various states --such as reasonable caps on non-economic damages-- substantially reduce the cost of insurance claims and, in turn, premiums.

Helland and Showalter (2009) examined the impact of malpractice reforms in the years 1983 and 1988 using Florida malpractice awards data. They used measure of liability risk based on incurred losses to estimate the impact of malpractice reform on physician labor market behavior (specifically the number of hours worked by doctors). They estimated the labor elasticity of liability exposure to be -0.285 for the pooled sample of physicians and -1.224 for physicians age 55 or older. This suggests that older physicians are substantially more sensitive to changes in liability risk than are younger physicians. Further, Helland and Showalter estimate that an increase of $\$ 1$ in expected liability should increase medical malpractice premiums by between $\$ .70$ and $\$ 1.05$.

Many articles in this area paint a rather bleak picture about future trends in medical liability insurance claims and premiums. The article "Chronic Pain Malpractice Claims on the Rise" 12 focuses on a presentation made by Kelly Pollak, MD, (University of Washington and Seattle Cancer Care Alliance) at the Anethesiology 2014 conference in New Orleans, LA. Using data from the Anesthesia Closed Claims Database, Dr. Pollak and her colleagues examined 10,367 malpractice claims. She noted: "Malpractice claims associated with chronic pain have increased in number and severity over the past three decades and they have increased out of proportion to the increase in pain anesthesiologists."

A 2011 study published in the New England Journal of Medicine ${ }^{13}$ found that "over a medical lifetime, most physicians across all specialties can expect at least 1 claim." The odds increase to $99 \%$ for physicians in the 5 most claim-prone specialties: neurosurgery, thoracic cardiovascular surgery, general surgery, orthopaedic surgery, and plastic surgery. Across specialties, both the likelihood of medical malpractice suits and the amount of indemnity payments vary significantly. Although the cumulative risk of a physician facing a medical malpractice claims over his (or her) career is high, most medical malpractice claims do not result in a plaintiff receiving a payment.

A 2013 study published on-line in JAMA Internal Medicine ${ }^{14}$ examined two insurers' pooled closed claims data from 1/1/2005-12/31/2009. The insurers provided malpractice coverage to most of the physicians in the State of Massachusetts during this 5 -year period. According to the study:

\footnotetext{
${ }^{11}$ Computed as follows: $87 \%$ x $94.5 \%$.

${ }^{12}$ Helwick, C. (2014). Chronic pain malpractice claims on the rise. Retrieved from http://www.medscape.com/viewarticle/833345 print.

${ }^{13}$ Jena, A., Seabury,S., Lakdawalla, D., and Chandra, A. (2011). Malpractice risk according to physician specialty. N Engl J Med 2011;365:629-

636. See also: Lowes, R, (2011). Most physicians will face malpractice claim by age 65 . Retrieved from http://www.medscape.com/viewarticle/748198 print.

${ }_{14}$ Schiff, G., Puopolo, A., Huben-Kearney, A., Yu, W., Keohane,,C., McDonough, P, Ellis, B., Bates, D., Biondolillo, M. (2013 ). Primary care closed claims experience of Massachusetts malpractice insurers. JAMA Intern Med. 2013;173(22):2063-2068. Retrieved from
} 
...there were 7224 malpractice claims of which $551(7.7 \%)$ were from primary care practices. Allegations were related to diagnosis in $397(72.1 \%)$, medications in $68(12.3 \%)$, other medical treatment in 41 $(7.4 \%) \ldots$ Primary care cases were significantly more likely to be settled $(35.2 \%$ vs $20.5 \%)$ or result in a verdict for the plaintiff $(1.6 \%$ vs $0.9 \%)$ compared with non-general medical malpractice claims $(P<.001)$.

Stated alternatively, while primary care cases accounted for less than 1 in 10 medical malpractice cases, these cases were far more likely to be either settled, or lost in a jury trial, when compared with non-general medical claims.

An on-line article by Emma Wallace et al. $(2013)^{15}$ reviewed 34 published studies of malpractice claims. These studies took place in the United States (15), U.K. (9), Australia (7), France (2), and Canada (1). The most common cause of malpractice claims across these studies involved missed or delayed diagnosis. This occurred in 26$63 \%$ of such claims. The next most common cause --representing $5.6-20 \%$ of such claims-- involved medication error.

A 2012 survey by the American Congress of Obstetricians and Gynecologists (ACOG) found that most ob/gyns took restrictive and/or defensive actions to avoid being sued. ${ }^{16}$ Of those obstetricians surveyed, " $18.1 \%$ saw fewer high-risk obstetric patients, $15.1 \%$ performed more cesarean deliveries, and $13.5 \%$ stopped performing vaginal birth after cesarean delivery." Of those practicing gynecology, " $12.4 \%$ performed fewer surgeries and $5.2 \%$ dropped major operations." On a somewhat brighter note, the "percentage of obstetrician/gynecologists who said they had altered their practice because of the risk or fear of getting sued decreased from $62.9 \%$ in 2009 to $57.9 \%$ in 2012." Also, malpractice insurance premiums as a percentage of revenue -along with the number of claims reported-- decreased somewhat from 2009 to 2012.

A study published in the Journal of the American College of Radiology (JACR) ${ }^{17}$ used linear regression to analyze National Practitioner Data Bank claims data from 1991 to 2009 to: "(1) define the magnitude of malpractice costs related to communication failures in test result notification and (2) determine if these costs are increasing significantly." The findings of Gale et al. suggest that claims payments have increased nationally each year by an average of $\$ 4.7$ million. Using medical malpractice claims data from the Controlled Risk Insurance Company/Risk Management Foundation for the period 2004 to 2008, the researchers found that "communication failures account for $4 \%$ of cases by volume and $7 \%$ of the total cost." To ward against increased liability risk stemming from communication failures in test result notification, the researchers recommend the use of semi-automated critical test result management systems.

In 2011, Ryan K. Orosco, MD, made a presentation ${ }^{18}$ to the American College of Surgeons 97 th Annual Clinical Congress in San Francisco, CA. In it, Dr. Orosco indicated that, although surgical malpractice payments over time have decreased in number, such payments have increased in amount. Using data from the National Practitioner Data Bank (NPDB), Dr. Orosco and his colleagues examined 58,518 claims from 1990 to 2006 and performed multivariate regression analysis upon selected predictors of payments in excess of \$1 million (using 2006 dollars.) Dr. Orosco noted that, with regard to surgical medical malpractice, the 4 states with the highest payment

http://archinte.jamanetwork.com/article.aspx?articleid=1741891. See also Lowes, R. (2013). Primary care malpractice cases 'more difficult to defend'. Retrieved from http://www.medscape.com/viewarticle/811898 print.

${ }^{15}$ Wallace, E., Lowry, J., Smith, S., Fahey, T. (2013). The epidemiology of malpractice claims in primary care: a systematic review. BMJ Open 2013. Retrieved from http://bmjopen.bmj.com/content/3/7/e002929.full . See also Brown, T. (2013). Missed diagnoses trigger primary care malpractice claims. Retrieved from http://www.medscape.com/viewarticle/808132 print.

Lowes, R. (2012). Malpractice suits continue to put ob/gyns on defensive. Medscape. Sep 12, 2012 . Retrieved from http://www.medscape.com/viewarticle/770777_print.

${ }_{17}$ Gale, B., Bissett-Siegel, D., Davidson, S., Juran, D. (2011). Failure to notify reportable test results: significance in medical malpractice. J Am Coll Radiol. 2011 ;8:776-779. See also Hand, L. (2011). Failure to report test results increases malpractice risk. Retrieved from http://www.medscape.com/viewarticle/752967 print.

${ }^{18}$ Orosco, R. (presenter) (2011); Talamini, J., Chang, D., \& Talamini, M. (authors) (2011); Tseng, J. \& Regenbogen, S. (session moderator and co-moderator) (2011); American College of Surgeons (ACS) 97th Annual Clinical Congress: session SF14. October 25, 2011. Retrieved from http://web2.facs.org/cc program planner/Detail Session 2011.cfm?CCYEAR=2011\&SESSION=SF14\&GROUP=SF1 . See also Helwick. C. (2011). Surgical malpractice claims drop, but pay-outs increase. Retrieved from http://www.medscape.com/viewarticle/753494_print . 
amounts (IL, CT, DE, \& WI) are all states without "caps" on damage awards, while the 4 states with the lowest payment amounts (MI, KS, SC, TX) are all states with such "caps."

In a study ${ }^{19}$ published in the New England Journal of Medicine, Jena et al. analyzed malpractice insurance data from 1991 through 2005 for 40,916 physicians with 233,738 physician-years of coverage. The researchers estimated the cumulative risk of physicians in various high- and low-risk specialties being sued. Among their findings:

Each year during the study period, $7.4 \%$ of all physicians had a malpractice claim, with $1.6 \%$ having a claim leading to a payment (i.e., $78 \%$ of all claims did not result in payments to claimants). The proportion of physicians facing a claim each year ranged from $19.1 \%$ in neurosurgery, $18.9 \%$ in thoracic-cardiovascular surgery, and $15.3 \%$ in general surgery to $5.2 \%$ in family medicine, $3.1 \%$ in pediatrics, and $2.6 \%$ in psychiatry.

The researchers estimated that "by the age of 65 years, $75 \%$ of physicians in low-risk specialties had faced a malpractice claim, as compared with $99 \%$ of physicians in high-risk specialties."

In a 2011 study $^{20}$ published in JAMA, Bishop et al. used data from the National Practitioner Data Bank from 2005 through 2009 to examine malpractice payments that result from adverse events occurring in inpatient and outpatient settings. The researchers performed trend analysis and a cross-sectional comparison of malpractice payments. Their findings suggest that patient safety initiatives should focus on both inpatient and outpatient care. In addition, such initiatives should focus upon taking steps to reduce the incidence of diagnostic error.

In a study ${ }^{21}$ of 2,416 physicians that appeared in the Archives of Internal Medicine, researchers from the Mt. Sinai School of Medicine asked physicians to assess the following statements:

1) "Doctors order more tests and procedures than patients need to protect themselves against malpractice suits," and

2) "Unnecessary use of diagnostic tests will not decrease without protections for physicians against unwarranted malpractice suits."

Approximately $91 \%$ of the physicians surveyed indicated they practiced defensive medicine to protect themselves against malpractice suits. This study found "no statistically significant differences between sex, geographic location, specialty category, or type of practice. The largest difference was that $92.6 \%$ of male physicians said they practice defensive medicine vs $86.5 \%$ of female physicians." The findings of this study suggest that, among physicians, the fear of lawsuits due to malpractice is widespread.

In a national survey, ${ }^{22}$ Lucas et al measured cardiologists' self-reported propensity to recommend hightech and/or invasive tests and treatments. The researchers found substantial variation in physician responses for some of the survey items. Among their findings:

\footnotetext{
${ }^{19}$ Jena,A., Seabury,S., Lakdawalla,D., and Chandra, A. (2011) N Engl J Med 2011; 365:629-636; DOI: 10.1056/NEJMsa1012370. Retrieved from http://www.nejm.org/doi/full/10.1056/NEJMsa1012370 . See also O'Riordan M. (2011). See also Cardiologists face above-average risk of malpractice suits. Retrieved from http://www.medscape.com/viewarticle/748223 print.

${ }_{20}$ Bishop,T., Ryan, A., Casalino, L. (2011). Paid malpractice claims for adverse events in inpatient and outpatient settings. JAMA. 2011;305(23):2427-2431. doi:10.1001/jama.2011.813. See also Lowes, R. (2011). Physician offices nearly as malpractice-prone as hospitals . Retrieved from http://www.medscape.com/viewarticle/744599 print .

${ }^{21}$ Bishop,T., Federman,A., Keyhani, S., (2010). Physicians' views on defensive medicine: a national survey. Arch Intern Med. 2010:170:10811084. See also Crane, M. (2010). New study finds $91 \%$ of physicians practice defensive medicine. Retrieved from http://www.medscape.com/viewarticle/724254 print.

${ }_{22}$ Lucas, F., Sirovich, B., Gallagher, P., Siewars, A., Wennberg, D. (2010). Variation in cardiologists' propensity to test and treat: is it associated with regional variation in utilization? Circ Cardiovasc Qual Outcomes 2010; DOI: 10.1161/CIRCOUTCOMES.108.840009. See also Stiles,S. (2010). Regional variation in cardiac cath rates linked to malpractice concern. Retrieved from http://www.medscape.com/viewarticle/720314_print.
} 
Variability in cardiologists' propensity to test and treat partly underlies regional variation in utilization of general health and cardiology services. The factor most closely associated with this propensity was fear of malpractice suits. This factor may be an appropriate target of intervention.

\section{Recent Developments}

The findings of a recent study and a survey provide good news about future trends in medical liability insurance claims and premiums. A 2014 study $^{23}$ in JAMA of paid malpractice claims against physicians found that, since 2002, such claims have decreased dramatically. Paid claims "decreased from 18.6 to 9.9 per 1,000 physicians per year between 2002 and 2013." The estimated average decrease in paid claims per MD per year was $6.3 \%$. The researchers used data from the National Practitioner Data Bank and the AMA's Physician Masterfile to track claims from 1994-2013. The study also noted that communication and alternative dispute resolution techniques used in a handful of communities showed promise in reducing paid claims.

In its annual survey of medical malpractice insurance, the Medical Liability Monitor found that premiums have decreased for the seventh straight year for three so-called "bellwether" specialties - obgyns, internists and general surgeons. One reason for the decline in premiums is the continued decline in malpractice claims per physician. Another is the increased employment of physicians by hospitals that self-insure. This survey also found that the cost of coverage varies widely by state. For example, quotes for standard coverage for general surgeons ranged from $\$ 10,868$ for a practice in Wisconsin to $\$ 190,829$ for one in Miami-Dade County Florida. Although premiums for these three specialties have fallen on average by $13 \%$ since 2008 , it should be noted that premium increases of $20 \%, 20 \%$, and $9 \%$ occurred in 2003,2004 , and 2005 , respectively ${ }^{24}$. A general decline in malpractice insurance premiums is expected to continue into $2015 .^{25}$

\section{The Patient Protection and Affordable Care Act}

The primary goals of the Patient Protection and Affordable Care Act (often referred to as Obamacare) include reforming the market for private insurance, expanding Medicare coverage to the working poor, providing affordable insurance coverage, and improving the process by which medical decisions are made. With regard to the first goal, insurance companies "must offer comparable policies at the same rates to all with relatively little variation allowed, not exclude preexisting conditions or cancel policies, and limit their rate increases" ${ }^{\text {"26 }}$. With regard to the second goal, the issue of expanding Medicaid to the working poor has resulted in litigation. In its landmark decision that upheld the constitutionality of the Patient Protection and Affordable Care Act, the Supreme Court also held that the decision to expand Medicaid to the working poor must be made on a state-by-state basis. ${ }^{27}$ As of early September, 2014, 27 states and the District of Columbia have opted to expand such Medicaid coverage $\mathrm{e}^{28}$. A third goal of the Patient Protection and Affordable Care Act is to help workers obtain affordable health insurance coverage. This law provides subsidies to many of the workers who otherwise would be ineligible for expanded Medicare coverage. A fourth goal focuses on improving the process by which medical decisions are made. This includes a focus on data-driven comparative effectiveness research, alternative delivery methods, and treatment alternatives.

The Patient Protection and Affordable Care Act is as ambitious as it is controversial. The October 1, 2013, debut of the health insurance exchange website known as www.healthcare.gov resulted in numerous user complaints that it "froze" repeatedly and made the process of signing up for health insurance both cumbersome and timeconsuming. Insurers and businesses alike have complained that the law is difficult to understand and administer. The implementation of several key provisions of this law has been delayed by executive order.

23 Mello, M., Studdert, D.,Kachalia, A. (2014). JAMA. 2014;312(20):2146-2155. doi:10.1001/jama.2014.10705.

See also Frellick, M. (2014). Steep drop in paid liability claims in past decade. Journal of American Medical Association. Retrieved from http://www.medscape.com/viewarticle/834206 print .

${ }^{24}$ Medical Liability Monitor. (10/10/14). http://medicalliabilitymonitor.com/news/2014/10/medical-liability-monitor-publishes-2014-annualsurvey-of-medical-malpractice-rates/. Accessed (4/22/15). See also Lowes, R. (2014). Medical malpractice insurance premiums nudge down again. Retrieved from http://www.medscape.com/viewarticle/833151 print .

${ }^{25}$ Page, L. (2014). 12 changes that will affect doctors' income in 2015. Retrieved from http://www.medscape.com/viewarticle/835123 print .

${ }^{26}$ Silvers, J. (2013). The affordable care act: objectives and likely results in an imperfect world, Ann Fam Med., 11(5) 402-405.

${ }^{27}$ United States Supreme Court (2012). National federation of independent business v. sebelius, 132 S.Ct 2566.

${ }^{28}$ See: http://www.advisory.com/daily-briefing/resources/primers/medicaidmap . 
The U.S. Supreme Court has agreed to hear a legal challenge to the way in which health insurance subsidies are administered. Most states have decided not to set up state health exchanges. In those states, residents rely on the federal health exchange marketplace to obtain coverage. Residents currently receive subsidies regardless of whether their state has set up its own state health exchange. However, the language of the Patient Protection and Affordable Care Act states that such subsidies relate to an "exchange established by the state". If this legal challenge prevails, residents in states that rely upon the federal marketplace will not be eligible to receive subsidies. Accordingly, the Patient Protection and Affordable Care Act is sometimes referred to as a "work in process". Although it is anticipated that this new law will result in more reliance on hospital-based providers, at this time, the effect it may have upon medical malpractice insurance premiums is unclear.

\section{Data and Estimation}

The issue of tort reform can be politically contentious. In many states, tort reform has been extended to include injuries arising from medical malpractice. For purposes of our analysis, we define "medical tort reform" as changes to state law involving medical malpractice that either: 1) restrict the ability of a party to file a personal injury lawsuit; or 2) place "caps" on personal injury damage awards.

Existing research in this area has set forth several competing hypotheses involving medical malpractice insurance premiums that are "directional" in nature. Hypothesis \#1 is that if medical malpractice awards increase, then medical malpractice insurance premiums will increase. Hypothesis \#2 is that if insurers' investment returns decrease, then medical malpractice insurance premiums will increase. Hypothesis \#3 is that if, for a given year, there is an increase in the total number of states that have, or have enacted, medical tort reform legislation, ${ }^{29}$ then medical malpractice insurance premiums will decrease.

In this article, we estimate real (i.e., inflation-adjusted) direct premiums per doctor (RDPPD) as a function of: 1) real (i.e., inflation-adjusted) direct losses per doctor (RDLPD); 2) several measures of the overall performance of investments; and 3) a dummy variable measuring existing statutory malpractice award limits within states each year. For purposes of our analysis, we use both a standard ordinary least squares (OLS), first-difference estimation, and distributed lag regression.

Because we use annual national-level data from 1975 to 2008 for all variables, we estimate parsimoniously to conserve degrees of freedom in our models. With regard to the independent variables, we could not find adequate data involving yearly total medical malpractice awards in the United States. While some awards are made available to the public, many are not. For example, many malpractice awards are structured as legal settlements subject to nondisclosure provisions. Accordingly, we use real (i.e., inflation-adjusted) direct losses paid per doctor as a "proxy" for yearly total medical malpractice awards. We use annual insurance industry data involving direct losses paid per doctor contained in a recent consumer health publication (Hunter, Cassell-Stiga, \& Doroshow, 2009). We obtain the monthly closing index value of the S\&P 500, Treasury bills, and Treasury bonds, calculate the continuous rate of return for each, and use each separately as a proxy for insurers' investment returns during that period ${ }^{30}$. For the independent variable measuring the presence of tort reform, we use original constructed data compiled by examining the laws of each state during the period 1975-2010. For a given year, if a state has a medical tort reform law on its books, a value of " 1 " is assigned. If not, the state is assigned a value of " 0 ". For a state to receive a " 1 ," there must be a law in effect that places a strict limit on non-economic damages (also referred to as "pain and suffering" awards). Each year, the sum of the values for all 50 states is computed as an indicator of the number of states with damage caps. The resulting number is used to track the prevalence of tort reform in the United States during the period 1975-2010.

During the period, the annual rate of return averaged 1) for Treasury bills, about 5.5\%;2) for the S\&P 500, about $8.5 \%$; and 3 ) for the entire stock market, more than $13 \%$ (see Table 1). During the period, on average, less

\footnotetext{
${ }^{29}$ For purposes of our analysis, we will assume that an increase in medical malpractice tort reform will result in a decrease in medical malpractice awards.

${ }^{30}$ Because we use rates of return, no inflation adjustment is required. 
than one additional state adopted medical malpractice non-economic damage caps per year. In addition, direct premiums (RDPPD) averaged more than twice the direct losses paid (RDLPD).

Since we are estimating with time series data, it is important to test for a unit root process in our data series. The validity of the OLS estimation process depends on the data being stationary. If the process is non-stationary, the use of OLS can produce spurious regression, upwardly biasing the t-stats and R-square. We perform a modified Dickey-Fuller t-test for a unit root in which the series has been transformed by a generalized least-squares regression (see Table 2). It tests if a variable follows a unit-root process. The null hypothesis is that the variable contains a unit root --a non-stationary process-- and the alternative is that the variable is generated by a stationary process. We test up to nine lagged periods, rejecting the null in only one of the nine at the 0.1 level of significance. However, several of the test statistics are only slightly outside the rejection region. For this reason, we present both the OLS and the first-difference regression results.

Let us first consider a parsimonious model that uses the rate of return on US Treasury bonds (TBONDS_ROR). ${ }^{31}$ The first model is estimated with all contemporaneous variables. The results are summarized in Table 3. The only variable that is a significant determinant of the direct premiums paid per doctor is the presence of more states with tort reform laws. For each additional state that adopts legislation limiting non-economic damages, premiums are reduced by $\$ 195$ per doctor per year. Higher rates of return are associated with lower premiums as well, but the impact is small and statistically insignificant for the contemporaneous period data. We estimate this equation with the average rate of return for Treasury bonds, Treasury bills, and the S \& P 500, but, in the standard OLS model, none of these measures of market return resulted in a p-value less than 0.51 . The variable known as direct losses per doctor (RDLPD) has the expected positive impact on insurance premiums. Each dollar lost per doctor is associated with $\$ 0.47$ in added premium costs per doctor. Variation in the three independent variables explains only about $19 \%$ of the variation in the insurance premiums.

The impacts of investments, insurance payouts, and state tort laws may take longer than a year to affect insurance rates, especially when insurance premiums are likely to be paid once a year. To account for the potential for a lagged impact on premium prices, we estimate models that use lagged independent variables as determinants. To conserve degrees of freedom, we only estimate models with up to five periods of lags. The model that provides the best overall fit based on R-squared is the one that lags direct losses two periods and state tort reform laws five periods. ${ }^{32}$ Treasury bonds are lagged four periods (see Tables $4 \& 5$ ). Treasury bills are lagged one period (see Table 5$)^{33}$. The impacts of the lagged right-hand side variables are both larger and more significant than those from the contemporaneous period.

Table 4 indicates that, when using Treasury bonds as a proxy for investment rate of return, one additional state adopting tort reform legislation results in an average $\$ 350$ decrease in malpractice premiums per doctor. This impact is significant at all typical confidence levels. The variable known as direct losses per doctor lagged two periods (L2_RDLPD) also has a significant impact upon yearly insurance premiums. This result suggests that if average losses increase by one dollar, premiums increase by more than what is required to offset the loss, or $\$ 1.33$. Curiously, the rate of return on Treasury bonds four periods prior results in higher, rather than lower, malpractice insurance premiums, suggesting that as returns on Treasury bonds increase, premiums rise as well; however, this result is not significant at the $10 \%$ level.

Treasury bonds represent longer-term financial instruments, whereas Treasury bills are primarily short-term instruments. If, in the regression, we substitute the rate of return on Treasury bills for that on Treasury bonds, we find that a higher rate of return on Treasury bills results in significantly lower insurance premiums in the current year. ${ }^{34}$ A one percentage point increase in the Treasury bills' rate of return reduces average malpractice insurance premiums by $\$ 642$ per doctor per year, as compared with $\$ 549$ for an additional state with tort reform legislation.

\footnotetext{
${ }^{31}$ Though not presented in our results in Table 3, we also estimate the impact of the rate of return from the S\&P 500; however, the impact was not significantly correlated in the contemporaneous period.

${ }^{32}$ The optimal lag length for rate of returns on investment varies with the investment used in the regression.

${ }^{33}$ Regressions using the S\&P 500 index are not presented since its inclusion produced no statistically significant impact on insurance premiums regardless of the lag period.

${ }^{34}$ In our model, we used contemporaneous rate of return on Treasury bills in Table 5, as opposed to the rate of return on Treasury bonds lagged four periods in Table 4.
} 
To account for potential non-stationary data, we estimate the first-difference model with and without a constant term and with and without lags. All but the differenced model with lagged Treasury bonds provide similar results to the regression without the constant term. These results tell a compelling story. Contemporaneously, tort reform and medical malpractice insurance premiums may be endogenous. Although we use state tort reform laws to explain insurance premiums, it is just as plausible that current period higher premiums may lead to a higher likelihood that a given state will adopt malpractice reform laws.

The positive impact of the first difference in tort reform in the equations without lags indicates that higher premiums are associated with malpractice reform laws; however, the lagged values of tort reform legislation cannot be endogenous. It would be incorrect to suggest that current malpractice premiums have an effect on tort reform legislation five periods earlier. Therefore, let us focus on the third equations in both Table 6 and 7 . These equations display a better overall fit than the fourth equations in both tables and the change in the Treasury bills' rates of return have a higher p-value in both models. The third equations in both Table 6 and 7 indicate that an increase in losses per doctor is associated with significantly higher premiums. The presence of tort reform is associated with a substantial reduction in insurance premiums, which is also significant to at least the $2 \%$ level. Furthermore, an increase in the rate of return on Treasury bills is associated with a substantial reduction in insurance premiums, but the impact falls just shy of the $1 \%$ level of significance. Table 5 performs OLS regression (with lags) using the rate of return on Treasury Bills. As the rate of return on Treasury Bills increases, premiums tend to decrease and such impact is statistically significant. Estimates of the impact of rates of return on medical malpractice insurance premiums are significant in one of three of our specifications. These results suggest that direct losses, tort reform, and, to a lesser extent, investments each play a role in the determination of malpractice insurance premiums.

\section{CONCLUSION}

We find that changes in the number of states with tort reform legislation appear to be the primary reason for changes in medical malpractice insurance premiums. Interestingly, however, malpractice reform laws do not produce their desired impacts immediately. Our estimates suggest that a legislative change in a given state may take up to five years to have its maximum impact upon medical malpractice insurance premiums.

We also find that direct losses are associated with higher insurance premiums. As is the case with tort reform legislation, the impact of higher or lower payouts takes time to appear in the form of premium changes. Higher average losses translate almost dollar-for-dollar into higher average premiums, and, in at least one of our models, the impact of a dollar lost per doctor two periods' prior results in more than a dollar increase in average premiums per doctor. This is consistent with the findings of Helland and Showalter (2009) in which an additional $\$ 1$ of expected losses can increase premiums by up to $\$ 1.05$ without controlling for the impact of investment rates of return.

We find that market rates of return are also associated with insurance premiums. However, the size and direction of the impacts depend upon the type of financial instruments measured, and the lag length of the returns. In some specifications, the magnitude of the impact of a one-percentage point change in the investment rate of return is comparable to the impact of the presence of tort reform in one additional state. Among measures of investment returns, the average rate of return for Treasury bills, a relatively short-term investment instrument, has the strongest correlation across all model specifications. Furthermore, the rates of return for investment instruments held by health insurers are likely to be exogenous in the equation (i.e., rates of return on Treasury securities are not likely to be determined by changes in malpractice premiums). Unfortunately, we do not have access to the actual investment portfolios of health insurance providers. Nevertheless, our results highlight that rates of return on short-term investments influence malpractice premiums independent of the existence of medical malpractice tort reform.

As mentioned earlier, a one percentage point increase in the rate of return of Treasury bills reduces real malpractice insurance premiums by $\$ 642$ per doctor, as compared with $\$ 549$ for an additional state enacting tort reform legislation. Taken together, the combined effect is $\$ 1,191$ per doctor/per year/per medical malpractice insurance policy. This represents $11.9 \%$ of the average annual cost of a medical malpractice insurance policy. ${ }^{35}$

\footnotetext{
${ }^{35}$ Our calculation of the percentage of the average annual cost of a medical malpractice insurance policy per doctor is inflation adjusted and uses Copyright by author(s); CC-BY 


\section{ACKNOWLEDGEMENTS}

The authors gratefully acknowledge the research assistance of Parvaneh Javanmard, Samuel Adam Cleek, and Mark Wills in the preparation of this manuscript.

\section{AUTHOR INFORMATION}

William J. Smith, Ph.D., is an Associate Professor of Economics in the Richards College of Business at the University of West Georgia. His primary research interests include urban economics, regional economics, and tax policy. Email: wjsmith@westga.edu

Tania A. Celis is a Research Assistant in Economics in the Richards College of Business at the University of West Georgia. Email: tcelis1@my.westga.edu

Bruce M. Bird, JD, CPA, is a Professor of Accounting in the Department of Accounting and Finance in the Richards College of Business at the University of West Georgia. He consults and writes frequently in the areas of taxation and tax policy. His articles have appeared in Journal of Taxation, CPA Journal, Tax Adviser, and other journals. E-mail: bbird@westga.edu (Corresponding author)

\section{REFERENCES}

Bishop,T., Ryan, A., Casalino, L. (2011). Paid malpractice claims for adverse events in inpatient and outpatient settings. JAMA. 2011;305(23):2427-2431. doi:10.1001/jama.2011.813.

Bishop,T., Federman,A., Keyhani, S., (2010). Physicians' views on defensive medicine: a national survey. Arch Intern Med. 2010:170:1081-1084.

Brown, T. (2013). Missed diagnoses trigger primary care malpractice claims. Retrieved from http://www.medscape.com/viewarticle/808132 print .

Crane, M. (2010). New study finds $91 \%$ of physicians practice defensive medicine. Retrieved from http://www.medscape.com/viewarticle/724254 print .

Dubai, L., Kaestner, R., and Waidmann, T. (2001). Medical malpractice liability and its effect on prenatal care utilization and infant health". Journal of Health Economics. 20 no.4, 591-612.

Frellick, M. (2014). Steep drop in paid liability claims in past decade. Journal of American Medical Association . Retrieved from http://www.medscape.com/viewarticle/834206 print .

Gale, B., Bissett-Siegel, D., Davidson, S., Juran, D. (2011). Failure to notify reportable test results: significance in medical malpractice. J Am Coll Radiol. 2011 ;8:776-779.

Gius, M. P. (1998). Using panel data to estimate the determinants of medical malpractice insurance premiums. Applied Economics Letters. 5(1), 37-39. doi: http://www.tandf.co.uk/journals/titles/13504851.asp .

Hand, L. (2011). Failure to report test results increases malpractice risk. Retrieved from http://www.medscape.com/viewarticle/752967 print .

Helland, E., \& Showalter, M. (2009). The impact of liability on the physician labor market. Journal of Law and Economics, 52(4), 635-663. doi: http://www.journals.uchicago.edu/JLE/home.html .

Helwick, C. (2014). Chronic pain malpractice claims on the rise. Retrieved from http://www.medscape.com/viewarticle/833345 print.

Helwick. C. (2011). Surgical malpractice claims drop, but pay-outs increase. Retrieved from http://www.medscape.com/viewarticle/753494 print .

Hillman, R., \& Cluff, L. (2003). Medical malpractice insurance: multiple factors have contributed to increased premium rates (GAO-03-702) United States General Accounting Office. Washington, D.C.

Hunter, J., Cassell-Stiga, G., \& Doroshow, J. (2009). True risk: medical liability, malpractice insurance and health care. Americans for Insurance Reform. New York, NY.

Jena,A., Seabury,S., Lakdawalla,D., and Chandra, A. (2011) N Engl J Med 2011; 365:629-636; DOI: 10.1056/NEJMsa1012370. Retrieved from http://www.nejm.org/doi/full/10.1056/NEJMsa1012370 .

2008 as the base year for prices. 
Kessler, D. (2006). The determinants of the cost of medical liability insurance. National Bureau of Economic Research: Stanford University Graduate School of Business.

Kilgore, M., Morrisey, M., \& Nelson, L. (2006). Tort law and medical malpractice insurance premiums. Inquiry, 43(3), 255-270. doi: http://www.inquiryjournal.org .

Lai, G., \& Witt, R. (1992). Changed insurer expectations: An insurance economics view of the commercial liability crisis under uncertainty. Journal of Insurance Regulation, 10(3), 292-342.

Lowes, R. (2014). Medical malpractice insurance premiums nudge down again. Retrieved from http://www.medscape.com/viewarticle/833151 print .

Lowes, R. (2013). Primary care malpractice cases 'more difficult to defend'. Retrieved from http://www.medscape.com/viewarticle/811898 print.

Lowes, R. (2012). Malpractice suits continue to put ob/gyns on defensive. Retrieved from http://www.medscape.com/viewarticle/770777 print .

Lowes, R, (2011). Most physicians will face malpractice claim by age 65 . Retrieved from http://www.medscape.com/viewarticle/748198 print .

Lowes, R. (2011). Physician offices nearly as malpractice-prone as hospitals. Retrieved from http://www.medscape.com/viewarticle/744599 print .

Lucas, F., Sirovich, B., Gallagher, P., Siewars, A., Wennberg, D. (2010). Variation in cardiologists' propensity to test and treat: is it associated with regional variation in utilization? Circ Cardiovasc Qual Outcomes 2010; DOI: 10.1161/CIRCOUTCOMES.108.840009.

Medical Liability Monitor. (10/10/14). http://medicalliabilitymonitor.com/news/2014/10/medical-liability-monitorpublishes-2014-annual-survey-of-medical-malpractice-rates/. Accessed (4/22/15).

Mello, M., Studdert, D.,Kachalia, A. (2014). JAMA. 2014;312(20):2146-2155. doi:10.1001/jama.2014.10705.

Neale, F., Eastman, K., \& Drake, P. (2009). Dynamics of the market for medical malpractice insurance. Journal of Risk and Insurance, 76(1), 221-247. .

O’Riordan M. (2011). Cardiologists face above-average risk of malpractice suits. Retrieved from http://www.medscape.com/viewarticle/748223 print.

Orosco, R. (presenter) (2011); American College of Surgeons (ACS) 97th Annual Clinical Congress: session SF14. October 25, 2011. Retrieved from http://web2.facs.org/cc program planner/Detail Session 2011.cfm?CCYEAR=2011\&SESSION=SF14\& GROUP=SF1.

Page, L. (2014). 12 changes that will affect doctors' income in 2015. Retrieved from http://www.medscape.com/viewarticle/835123 print.

Schiff, G., Puopolo, A., Huben-Kearney, A., Yu, W., Keohane, C., McDonough, P, Ellis, B., Bates, D., Biondolillo, M. (2013). Primary care closed claims experience of Massachusetts malpractice insurers. JAMA Intern Med. 2013;173(22):2063-2068. Retrieved from http://archinte.jamanetwork.com/article.aspx?articleid=1741891.

Silvers, J. (2013). The affordable care act: objectives and likely results in an imperfect world. Ann Fam Med., 11(5) 402-405.

Stiles, S. (2010). Regional variation in cardiac cath rates linked to malpractice concern. Retrieved from http://www.medscape.com/viewarticle/720314 print .

Talamini, J., Chang, D., \& Talamini, M. (authors) (2011); American College of Surgeons (ACS) 97th Annual Clinical Congress: session SF14. October 25, 2011. Retrieved from http://web2.facs.org/cc program planner/Detail Session 2011.cfm?CCYEAR=2011\&SESSION=SF14\& GROUP=SF1

Tseng, J. \& Regenbogen, S. (session moderator and co-moderator) (2011); American College of Surgeons (ACS) 97th Annual Clinical Congress: session SF14. October 25, 2011. Retrieved from http://web2.facs.org/cc program planner/Detail Session 2011.cfm?CCYEAR=2011\&SESSION=SF14\& GROUP $=\mathrm{SF} 1$

Bishop,T., Federman,A., Keyhani, S., (2010). Physicians' views on defensive medicine: a national survey. Arch Intern Med. 2010:170:1081-1084.

Viscusi, W., \& et al. (1993). The effect of 1980 s tort reform legislation on general liability and medical malpractice insurance. Journal of Risk and Uncertainty. 6(2), 165-186. http://www.springerlink.com/link.asp?id=100299 
Wallace, E., Lowry, J., Smith, S., Fahey, T. (2013). The epidemiology of malpractice claims in primary care: a systematic review. BMJ Open 2013. Retrieved from http://bmjopen.bmj.com/content/3/7/e002929.full United States Supreme Court, (2012). National federation of independent business v. sebelius, 132 S.Ct 2566. 


\section{TABLES}

Table 1. Descriptive Statistics for Selected Variables

\begin{tabular}{|c|c|c|c|c|}
\hline Variable & Mean & St. Dev. & Min & Max \\
\hline RDPPD & 15819.14 & 3675.213 & 10970.23 & 22881.47 \\
\hline RDLPD & 7084.916 & 1807.136 & 3231.54 & 9425.2 \\
\hline STATE_TORT & 16.52941 & 8.951842 & 2 & 29 \\
\hline NEWSTATETORT & 0.852941 & 2.002004 & 0 & 11 \\
\hline S\&P_ROR & 8.508857 & 17.14148 & -37.28 & 34.52 \\
\hline STOCKROR & 13.1342 & 17.0702 & -36.58 & 37.2 \\
\hline TBILLSROR & 5.4797 & 3.1919 & 0.13 & 14.3 \\
\hline TBONDSROR & 8.3236 & 10.1672 & -11.12 & 32.81 \\
\hline
\end{tabular}

Table 2. Modified Dickey-Fuller T-test Results

\begin{tabular}{|c|c|c|c|c|}
\hline Lags & Test Statistic & $1 \%$ & $5 \%$ & $10 \%$ \\
\hline 9 & -2.775 & -3.77 & -2.811 & -2.388 \\
\hline 8 & -2.278 & -3.77 & -2.788 & -2.406 \\
\hline 7 & -1.398 & -3.77 & -2.814 & -2.46 \\
\hline 6 & -1.707 & -3.77 & -2.879 & -2.542 \\
\hline 5 & -1.722 & -3.77 & -2.971 & -2.643 \\
\hline 4 & -2.346 & -3.77 & -3.08 & -2.754 \\
\hline 3 & -2.792 & -3.77 & -3.195 & -2.866 \\
\hline 2 & -2.666 & -3.77 & -3.305 & -2.97 \\
\hline 1 & -2.931 & -3.77 & -3.4 & -3.058 \\
\hline
\end{tabular}

Table 3. OLS Regression Results

\begin{tabular}{lccc}
\hline \multicolumn{1}{c}{ Variable } & Coef. & t-stat & p-val \\
\hline RDLPD & 0.470642 & 1.26 & 0.217 \\
STATES_TORT & -195.247 & -2.63 & 0.013 \\
TBONDS_ROR & -13.0057 & -0.21 & 0.837 \\
CONSTANT & 15827.63 & 6.45 & 0 \\
R-Sq & 0.1894 & & \\
\hline
\end{tabular}

Table 4. OLS Regression Results with Lags

\begin{tabular}{lccc}
\multicolumn{1}{c}{ (Using Treasury Bonds) } & p-val \\
\hline \multicolumn{1}{c}{ Variable } & Coef. & t-stat & 0.000 \\
\hline L2_RDLPD & 1.336408 & 5.00 & 0.000 \\
L5_STATES_TORT & -349.713 & -7.60 & 0.126 \\
L4_TBONDS_ROR & 56.41591 & 1.58 & 0.000 \\
CONSTANT & 9701.303 & 4.98 & \\
R-Sq & 0.7681 & & \\
\hline
\end{tabular}

Table 5. OLS Regression Results with Lags

\begin{tabular}{lccc}
\multicolumn{1}{c}{ (Using Treasury Bills) } & p-val \\
\hline \multicolumn{1}{c}{ Variable } & Coef. & t-stat & 0.008 \\
\hline L2_RDLPD & 0.902262 & 2.88 & 0.00 \\
L5_STATES_TORT & -549.608 & -6.82 & 0.013 \\
TBILLS_ROR & -642.051 & -2.67 & 0.00 \\
CONSTANT & 20035.42 & 4.67 & \\
R-Sq & 0.8016 & & \\
\hline
\end{tabular}


Table 6. Differenced Regression Results with and without Lags

\begin{tabular}{|c|c|c|c|}
\hline Dep. Variable = D_RDPPD & Coef. & t-stat & p-val \\
\hline D_RDLPD & 0.861 & 1.830 & 0.077 \\
\hline D_STATES_TORT & 378.376 & 2.850 & 0.008 \\
\hline D_TBILLS_ROR & -249.017 & -1.580 & 0.125 \\
\hline CONSTANT & -546.053 & -1.930 & 0.063 \\
\hline $\mathrm{R}-\mathrm{Sq}$ & 0.332 & & \\
\hline D_RDLPD & 0.931 & 1.920 & 0.065 \\
\hline D_STATES_TORT & 412.061 & 3.020 & 0.005 \\
\hline D_TBONDS_ROR & 12.493 & 0.700 & 0.491 \\
\hline CONSTANT & -549.148 & -1.880 & 0.071 \\
\hline $\mathrm{R}-\mathrm{Sq}$ & 0.286 & & \\
\hline D_L2_RDLPD & 0.881 & 1.950 & 0.063 \\
\hline D_L5_STATES_TORT & -335.787 & -2.600 & 0.016 \\
\hline D_TBILLS_ROR & -264.971 & -1.590 & 0.125 \\
\hline CONSTANT & -10.495 & -0.040 & 0.971 \\
\hline $\mathrm{R}-\mathrm{Sq}$ & 0.369 & & \\
\hline D_L2_RDLPD & 2.561 & 2.080 & 0.048 \\
\hline D_L5_STATES_TORT & 157.787 & 0.440 & 0.664 \\
\hline D_L4_TBONDS_ROR & 51.741 & 1.080 & 0.289 \\
\hline CONSTANT & 15020.000 & 19.920 & 0.000 \\
\hline $\mathrm{R}-\mathrm{Sq}$ & 0.163 & & \\
\hline
\end{tabular}

Table 7. Differenced Regression Results with and without Lags

\begin{tabular}{|c|c|c|c|}
\hline Dep. Variable $=$ D_RDPPD & Coef. & t-stat & p-val \\
\hline D_RDLPD & 0.762 & 1.560 & 0.129 \\
\hline D_STATES_TORT & 280.139 & 2.190 & 0.037 \\
\hline D_TBILLS_ROR & -242.647 & -1.470 & 0.151 \\
\hline $\mathrm{R}-\mathrm{Sq}$ & 0.253 & & \\
\hline D_RDLPD & 0.828 & 1.650 & 0.109 \\
\hline D_STATES_TORT & 311.764 & 2.390 & 0.023 \\
\hline D_TBONDS_ROR & 10.453 & 0.560 & 0.578 \\
\hline$\overline{\mathrm{R}-\mathrm{Sq}}$ & 0.208 & & \\
\hline D_L2_RDLPD & 0.879 & 2.000 & 0.057 \\
\hline D_L55_STATES_TORT & -337.469 & -2.850 & 0.009 \\
\hline D_TBĒLLS_ROR & -264.482 & -1.620 & 0.117 \\
\hline $\mathrm{R}-\mathrm{Sq}$ & 0.375 & & \\
\hline D_L2_RDLPD & 6.967 & 1.400 & 0.173 \\
\hline D_L5_STATES_TORT & 3145.298 & 2.350 & 0.027 \\
\hline D_L4_TBO-TBNDS̄ROR & 209.611 & 1.090 & 0.288 \\
\hline $\mathrm{R}-\mathrm{Sq}^{-}$ & 0.208 & & \\
\hline
\end{tabular}




\section{APPENDIX 1.}

Figure 1. Direct Premiums Per Doctor (2008 Dollars) ${ }^{36}$

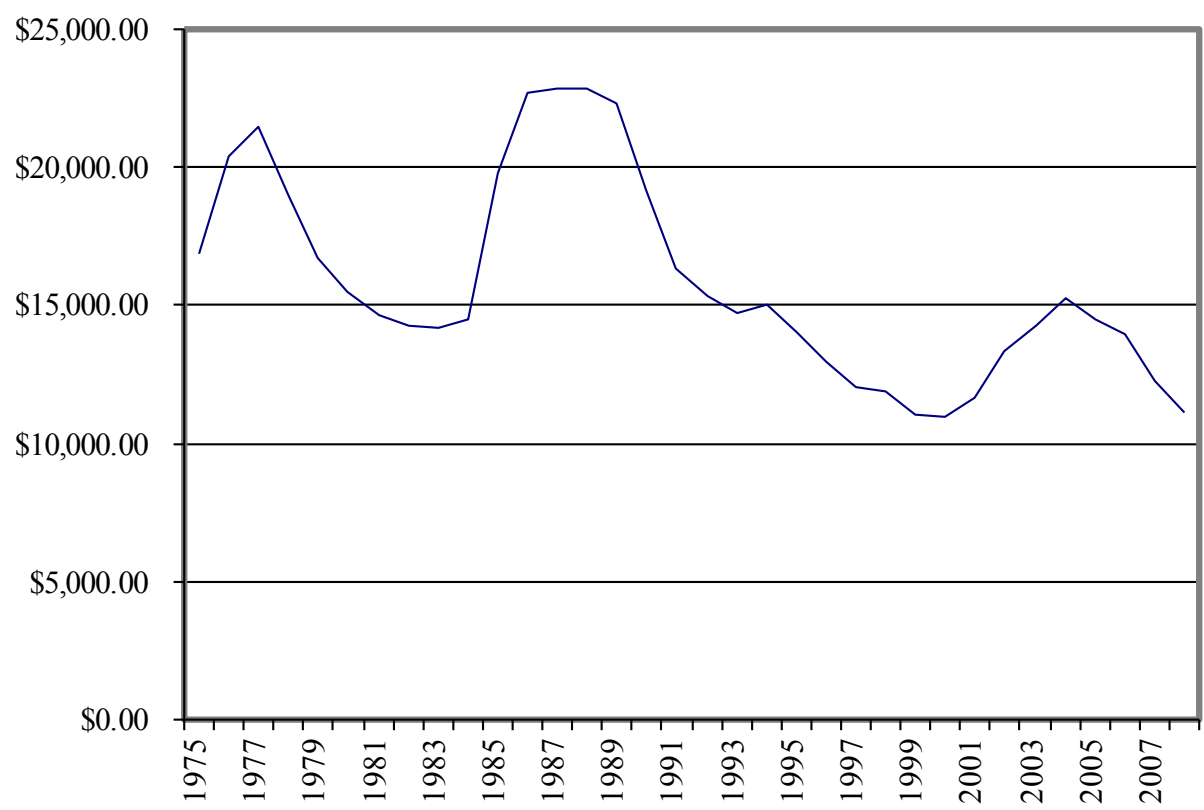

${ }^{36}$ Data obtained from a report by Americans for Insurance Reform entitled “ True Risk: Medical Liability, Malpractice Insurance and Health Care", (Hunter, Cassell-Stiga, \& Doroshow, 2009) . 